\title{
Prediction of Solid Polycyclic Aromatic Hydrocarbons Solubility in Water with the NRTL-PR Model
}

\author{
Joan Escandell $^{\mathrm{a}}$, Isabelle Raspo ${ }^{\mathrm{b}}$, Evelyne Neau $^{\mathrm{a}}$

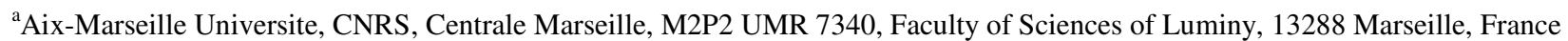 \\ b Aix-Marseille Universite, CNRS, Centrale Marseille, M2P2 UMR 7340, Technopôle de Château-Gombert, 13451 Marseille, France
}

\begin{abstract}
The accurate prediction of high pressure phase equilibria is crucial for the development and the design of chemical engineering processes. Among them the modeling of complex systems, such as petroleum fluids with water, has become more and more important with the exploitation of reservoirs in extreme conditions. The aim of this work is to explore the capability of the NRTL-PR model to predict the solubility of solid polycyclic aromatic hydrocarbons in water. For this purpose, we first validate our methodology for fluid phase equilibria predictions of aromatic hydrocarbons and gas $\left(\mathrm{CO}_{2}, \mathrm{C}_{2} \mathrm{H}_{6}\right)$ mixtures. Finally, we consider the prediction of the solid solubility of PAH in water, by fitting group parameters either only on SLE data or on both LLE and SLE data of aromatic hydrocarbon-water binary systems.
\end{abstract}

Keywords: solubility; solid-liquid equilibrium; EoS/G ${ }^{\mathrm{E}}$ approach; NRTL-PR model; polycyclic aromatic hydrocarbons; water.

\section{Introduction}

Polycyclic aromatic hydrocarbons (PAH) are very toxic substances which are often generated by human activities. They can be found in hydrocarbon-contaminated waste sites or in the sea after oil discharges by ships. They are also produced by offshore oil and gas exploration [1] and by several combustion processes [2,3], among others. Because these pollutants accumulate in soils and sediments and are persistent in the environment, it is crucial to understand their transport and transformation processes [4]. The solubility in water is an important transport property in the potential distribution of these compounds throughout the hydrologic system. Besides, the solubility is also necessary for the design of extraction processes of PAH with subcritical water $[5,6]$ since it provides the extractability limit which can be used. Therefore, a good representation of solid-liquid equilibria in water-PAH mixtures is essential for many practical applications; but PAH are highly hydrophobic compounds and, consequently, an accurate prediction of their very low solubilities is difficult to obtain.

In literature, models proposed for the calculation of non-polar hydrophobic compound aqueous solubility are essentially based on empirical or semi-empirical equations, which do not allow accurate results at both low and high temperatures [7]. However, for some years, a few papers were concerned with the modeling of solid-liquid equilibria in water-PAH systems by means of equations of state and $\mathrm{G}^{\mathrm{E}}$ models. Fornari et al. [8] compared the accuracy of the original UNIFAC, the modified version of Dortmund and the A-UNIFAC models, the latter including association effects between groups, for the representation of the solubility of solid PAH in subcritical water. These 
authors showed that the modified UNIFAC model gives a better prediction than the A-UNIFAC one, provided that the interaction parameters between water and aromatic groups are optimized by taking into account SLE data in the parameter fitting procedure. More recently, the CPA EoS, which adds an association term to the SRK equation of state, was applied by Oliveira et al. [9] to the modeling of the aqueous solubility of PAH. The major advantage of EoS based models, such as CPA, compared to $\mathrm{G}^{\mathrm{E}}$ models, such as UNIFAC, is to allow solubility predictions in a wide range of temperature and pressure, and especially under high pressures. Oliveira et al. showed that a good representation of the solubility of PAH can be obtained by fitting the solvation parameter for each binary water-PAH system on SLE data.

The purpose of this work is to explore the capability of the NRTL-PR model $[10,11]$ to predict solid-liquid equilibria (SLE) in water-PAH mixtures. This model is based on the EoS $/ \mathrm{G}^{\mathrm{E}}$ approach in which the Peng-Robinson equation of state is associated with the generalized NRTL excess Gibbs energy model [12]. In this formalism, binary interaction parameters are estimated from group contributions providing a totally predictive EoS. In order to validate the approach, the NRTL-PR model is first applied to the prediction of vapor-liquid equilibria (VLE) and of the solid solubility in supercritical fluids (SFE) of aromatic hydrocarbons with carbon dioxide or ethane. Then we investigate the capability of the model to predict both liquid-liquid equilibria (LLE) of aromatic hydrocarbons in water and the very low solubilities of PAH (SLE).

\section{Modeling}

\subsection{Solid-fluid equilibrium}

Solid-fluid equilibrium of binary mixtures of solvent(1)-PAH(2) is described assuming that the solid phase is pure $\mathrm{PAH}(2)$. The equilibrium condition for this component is thus written as:

$$
g_{2}^{S}(T, P)=g_{2}^{F}(T, P, x)
$$

where $g_{2}^{S}(T, P)$ and $g_{2}^{F}(T, P, x)$ are the molar Gibbs free energies of the pure solid (2) and of the solute in the fluid mixture, under the same temperature and pressure conditions; they are calculated by the following equations:

$$
\begin{aligned}
& g_{2}^{S}(T, P)=g_{2}^{S}\left(T, P^{r e f}\right)+v_{2}^{S}\left(P-P^{r e f}\right) \\
& g_{2}^{F}(T, P, x)=g_{2}^{*}\left(T, P^{r e f}\right)+R T \ln \left[\varphi_{2}(T, P, x) \frac{P}{P^{r e f}} x_{2}\right]
\end{aligned}
$$

with: $P^{r e f}$ a reference pressure, $v_{2}^{S}$ the molar volume of the solid, $g_{2}^{*}\left(T, P^{r e f}\right)$ the Gibbs free energy of pure compound 2 in the standard state and $\varphi_{2}(T, P, x)$ the fugacity coefficient in the fluid phase. The subcooled liquid pressure, $P^{s c l}$, is chosen as the reference pressure, so that the term $g_{2}^{S}\left(T, P^{r e f}\right)$ in Eq. (2) can be obtained from the Gibbs free energy of 2 as pure liquid, $g_{2}^{L}\left(T, P^{s c l}\right)$, considering the fusion properties: 


$$
g_{2}^{S}\left(T, P^{s c l}\right)=g_{2}^{L}\left(T, P^{s c l}\right)-\Delta_{f u s} G_{2}\left(T, P^{s c l}\right)
$$

with:

$$
g_{2}^{L}\left(T, P^{s c l}\right)=g_{2}^{*}\left(T, P^{s c l}\right)+R T \ln \varphi_{2}\left(T, P^{s c l}\right)
$$

and:

$$
\begin{aligned}
\Delta_{f u s} G_{2}\left(T, P^{s c l}\right)= & \Delta_{f u s} H_{2}\left(T_{m 2}, P_{0}\right)\left[1-\frac{T}{T_{m 2}}\right]+\int_{T_{m 2}}^{T} \Delta C_{P 2}\left(T, P_{0}\right) d T \\
& -T \int_{T_{m 2}}^{T} \Delta C_{P 2}\left(T, P_{0}\right) \frac{d T}{T}+\Delta_{f u s} v_{2}(T)\left(P^{s c l}-P_{0}\right)
\end{aligned}
$$

where $P_{0}$ is the atmospheric pressure, $\Delta_{f u s} H$ is the fusion enthalpy of the pure solute at its normal melting temperature $T_{m}, \Delta C_{P}$ is the difference in heat capacity at constant pressure between the subcooled liquid and solid forms of the pure solute at temperature $T$ and $\Delta_{f u s} v$ is the fusion molar volume. As is usually done [13-15], in order to simplify Eq. (6), $\Delta C_{P}$ is assumed to be independent of temperature and equal to the value at $T_{m}$ so that $\Delta_{f u s} G_{2}\left(T, P^{s c l}\right)$ is given by:

$$
\begin{aligned}
\Delta_{f u s} G_{2}\left(T, P^{s c l}\right) & =\Delta_{f u s} H_{2}\left(T_{m 2}, P_{0}\right)\left[1-\frac{T}{T_{m 2}}\right]-\Delta C_{P 2}\left(T_{m 2}, P_{0}\right)\left[T_{m 2}-T+T \ln \frac{T}{T_{m 2}}\right] \\
& +\Delta_{f u s} v_{2}(T)\left(P^{s c l}-P_{0}\right)
\end{aligned}
$$

The last two terms involving $\Delta C_{P}$ and $\Delta_{\mathrm{fus}} v$ are neglected since they are usually small compared to the first one, especially for PAH; indeed, experimental values of $\Delta C_{P}\left(T_{m}, P_{0}\right)$ are very low for these compounds $[13,15]$. Studies about the influence of $\Delta C_{P}$ approximations on the estimation of solid solubility were reported in literature for several classes of components (see for example [13-15]). They showed that assuming $\Delta C_{P}=0$ in Eq. (7) for PAH doesn't lead to deteriorated predictions of solubilities and besides, Pappa et al. [15] recommended the use of this approximation. Furthermore, we checked that, for the set of solutes considered in this work, the term involving $\Delta C_{P}$ was more than ten times lower than the fusion enthalpy term.

The introduction of Eqs. (2-7) in Eq. (1) leads to the following expression for the solubility of component 2:

$$
x_{2}=\frac{\varphi_{2}\left(T, P^{s c l}\right)}{\varphi_{2}\left(T, P^{s c l}, x\right)} \frac{P^{s c l}}{P} \exp \left[\frac{v_{2}^{S}\left(P-P^{s c l}\right)}{R T}-\frac{\Delta_{f u s} H_{2}\left(T_{m 2}, P_{0}\right)}{R}\left(\frac{1}{T}-\frac{1}{T_{m 2}}\right)\right]
$$

In this work, the fugacity coefficients of component 2 as pure liquid, $\varphi_{2}(T, P)$, and in the fluid mixture, $\varphi_{2}(T, P, x)$ are computed using the NRTL-PR model.

\subsection{The NRTL-PR model}

The NRTL-PR model is based on the Peng-Robinson equation of state [16]: 


$$
P=\frac{R T}{v-b}-\frac{a}{v^{2}+2 b v-b^{2}}
$$

in which the attractive term $a$ is estimated using the EoS $/ \mathrm{G}^{\mathrm{E}}$ approach based on the generalized reference state proposed in [17]:

$$
\alpha=\frac{a}{b R T}=\sum_{i} \alpha_{i} x_{i}-\frac{1}{0.53}\left[\frac{g^{E}}{R T}-\sum_{i} x_{i} \ln \frac{r_{i}}{r}\right]
$$

where $b$ is the covolume, $b=\sum_{i} x_{i} b_{i}, r_{i}$ and $r=\sum_{i} x_{i} r_{i}$ are the volume area factors characteristic of lattice fluid models and $g^{E}$ is the excess Gibbs energy expressed, with the generalized NRTL equation [12], as:

$$
g^{E}=R T \sum_{i} x_{i} \ln \frac{r_{i}}{r}+\sum_{i} x_{i} q_{i} \frac{\sum_{j} x_{j} q_{j} G_{j i} \Gamma_{j i}}{\sum_{l} x_{l} q_{l} G_{l i}}, G_{j i}=\exp \left(-\alpha_{0} \Gamma_{j i} / R T\right)
$$

So that:

$$
\alpha=\sum_{i} \alpha_{i} x_{i}-\frac{1}{0.53}\left[\frac{g_{\text {res }}^{E}}{R T}\right] \quad, \quad g_{\text {res }}^{E}=\sum_{i} x_{i} q_{i} \frac{\sum_{j} x_{j} q_{j} G_{j i} \Gamma_{j i}}{\sum_{l} x_{l} q_{l} G_{l i}}
$$

In the above equation, $\alpha_{0}$ is the non randomness factor $\left(\alpha_{0}=-1\right)$ and $q_{i}$ are the lattice fluid surface area parameters, estimated from the UNIFAC subgroups $Q_{k}$ :

$$
q_{i}=\sum_{k} v_{i k} Q_{k}
$$

with $v_{i k}$ the number of subgroup $k$ in a molecule $i$. The group contribution and the surface area parameters $Q_{k}$ considered in the NRTL-PR model are indicated in Table 1. It must be noted that no distinction is made between substituted single benzene ring carbons and fused-ring carbons. In Eqs. (11-12) the binary interaction parameters $\Gamma_{j i}$ are computed by means of a group contribution [10] which makes the NRTL-PR equation a totally predictive model:

$$
\Gamma_{j i}=\sum_{K} \theta_{i K} \sum_{L}\left(\theta_{j L}-\theta_{i L}\right) \Gamma_{L K}, \quad \theta_{i K}=\sum_{k} v_{i k(K)} \frac{Q_{k}}{q_{i}} \quad \text { with }: \quad \Gamma_{K K}=0, \Gamma_{K L} \neq \Gamma_{L K}
$$

where $\theta_{i K}$ is the probability that a contact from a molecule $i$ involves a main group $K$ and $v_{i k(K)}$ is the number of subgroup $k$ belonging to the main group $K$ in a molecule $i$. The group interaction parameters $\Gamma_{L K}$ depend on temperature with the following equation:

$$
\Gamma_{L K}=\Gamma_{L K}^{(0)}+\Gamma_{L K}^{(1)}\left(\frac{T_{0}}{T}-1\right) \text { with } T_{0}=298.15 \mathrm{~K}
$$


Finally, the model requires the estimation of pure component parameters: the attractive term $a_{i}$ and the covolume $b_{i}$ (necessary to calculate $\alpha_{i}$ in Eq. (12)) are estimated from the critical temperature and pressure, $T_{c i}$ and $P_{c i}$ respectively, by the formulae:

$$
a_{i}=0.4572 \frac{R^{2} T_{c_{i}}^{2}}{P_{c_{i}}} f\left(T_{r}\right), b_{i}=0.0778 \frac{R T_{c_{i}}}{P_{c_{i}}}
$$

where $T_{r}$ is the reduced temperature, $T_{r}=T / T_{c_{i}}$, and $f\left(T_{r}\right)$ is the generalized Soave function [20]:

$$
f\left(T_{r}\right)=\left[1+m\left(1-T_{r}^{\gamma}\right)\right]^{2}
$$

For hydrocarbons and non associating compounds, we used the original Soave function [21], corresponding to $\gamma=0.5$, and the parameter $m$ correlated to the acentric factor $\omega$ through the generalized expression proposed by Robinson and Peng [22]:

$$
\left\{\begin{array}{l}
m=0.37464+1.54226 \omega-0.26992 \omega^{2} \text { if } \omega<0.49 \\
m=0.379642+1.48503 \omega-0.164423 \omega^{2}+0.016666 \omega^{3} \text { if } \omega \geq 0.49
\end{array}\right.
$$

On the other hand, for associating compounds, the $\gamma$ and $m$ parameters were fitted on saturation properties as proposed in [20], which allows highly improved vapor pressure representations. For water the fitted values are $: \gamma=0.65, m=0.6864$.

With the NRTL-PR equation, the fugacity coefficient of a component $i$ is given by the following relation:

$$
\ln \varphi_{i}=-\ln Z(1-\eta)+(Z-1) \frac{1}{b}\left(\frac{\partial n b}{\partial n_{i}}\right)_{n_{j}}-\frac{1}{2 \sqrt{2}} \ln \left(\frac{1+(1+\sqrt{2}) \eta}{1+(1-\sqrt{2}) \eta}\right)\left(\frac{\partial n \alpha}{\partial n_{i}}\right)_{T, n_{j}}
$$

where $Z$ is the compressibility factor, $\eta=b / v$ and :

$$
\left(\frac{\partial n \alpha}{\partial n_{i}}\right)_{T, n_{j}}=\frac{a_{i}}{b_{i} R T}-\frac{1}{0.53}\left(\frac{\partial n g_{\text {res }}^{E}}{\partial n_{i}}\right)_{T, n_{j}}
$$

\section{Results}

The set of solvents and PAH considered in this work is given in Table 2, together with the values of the pure component properties. For PAH, the normal melting temperatures, $T_{m}$, and fusion enthalpies at melting point, $\Delta_{f u s} H$, as well as the solid volumes, $v_{2}^{s}$, were taken from literature.

\subsection{Solubility of PAH in supercritical fluids}

As already mentioned in the introduction, PAH are highly hydrophobic compounds. Therefore, an accurate representation of their very low solubilities in water is very difficult to obtain. As a 
consequence, water-PAH systems are not the most appropriate to check if a model is able to predict correctly solid-fluid equilibria. Thus, in order to validate the approach proposed in section 2 , we first considered the solubility of PAH in supercritical fluids; indeed, as can be seen in Tables 3 and 4 for $\mathrm{CO}_{2}$ and ethane, the experimental values are about three orders of magnitude higher than those in liquid water.

The calculation of solid-fluid equilibria of $\mathrm{CO}_{2}-\mathrm{PAH}$ and ethane-PAH mixtures with the NRTLPR model (Eq. 12) requires fitting the EoS binary parameters $\Gamma_{\text {aromatic, } \mathrm{CO} 2}$ and $\Gamma_{\text {aromatic,C2H6 }}$ (Eqs. 14, 15) taking into account simultaneously VLE and SFE data. Results thus obtained on PAH solubilities in supercritical carbon dioxide and ethane are reported respectively in Tables 3 and 4. For almost all mixtures, mean deviations are smaller than $30 \%$, except for some heavier compounds involving at least three benzene rings and exhibiting lower solubilities.

Figure 1 illustrates the prediction of solubilities, with respect to pressure, for the most representative systems in the range of experimental temperature. It can be seen that for mixtures of naphthalene, pyrene, phenanthrene, fluorene and biphenyl with $\mathrm{CO}_{2}$, as well as naphthalene with ethane, predictions with the NRTL-PR model are in very good agreement with experimental data. Figure 1d, concerning anthracene, pyrene and phenanthrene with supercritical ethane, shows that, despite higher deviations, a satisfactory representation of the solubilities is obtained. For measurements made in the vicinity of the mixture lower critical endpoint (Fig. 1a), the strong variation of the solubility with respect to pressure and the retrograde solubility phenomenon are accurately described.

To ensure that VLE predictions were not deteriorated by considering SFE data during parameter fitting procedure, we represent in Fig. 2 VLE for aromatic hydrocarbons. Figures $2 \mathrm{a}$ and $2 \mathrm{~b}$ for $\mathrm{CO}_{2}-$ benzene and ethane-toluene highlight that results are similar to those previously published [11] for single benzene ring molecules. Furthermore, as shown in Figs. $2 \mathrm{c}$ and 2d, satisfactory phase envelopes are calculated for gas-PAH systems, although experimental data are not available in the whole composition range.

We can therefore conclude that the NRTL-PR model is able to accurately estimate VLE of aromatic hydrocarbons and solubilities of PAH in solvents with the same set of parameters.

\subsection{Application to the solubility of PAH in liquid water}

The calculation of SLE of water-PAH mixtures with the NRTL-PR model (Eq. 12) also requires the values of the EoS binary parameters $\Gamma_{\text {aromatic,H2O }}$ and $\Gamma_{H 2 O \text {,aromatic }}$ (Eqs. 14, 15).

In a first step, the modeling was performed by using the parameter values previously obtained [11] by correlating LLE for a set of 23 binary mixtures of aromatic hydrocarbons with water; results obtained in this case were rather satisfactory with relative deviations on the mole fractions of $12.43 \%$ for water in the organic phase and $21.70 \%$ for hydrocarbons in the aqueous phase. Figure 3 illustrates typical LLE behavior for benzene and m-xylene in water with the NRTL-PR [LLE] using LLE parameters. As expected, the prediction of SLE using these parameters was not satisfactory. 
In order to check the capability of the model to correlate water-PAH SLE, the EoS binary parameters $\Gamma_{L K}$ and $\Gamma_{K L}$ were fitted to SLE data only; deviations $\Delta \mathrm{x}_{2} / \mathrm{x}_{2} \%$ [SLE] thus obtained are given in Table 5 and solubility curves for water-acenaphtene and water-phenanthrene are shown in Fig. 4. Qualitatively good results are obtained, with nevertheless an overestimation of solubilities below $10^{-7}$.

Finally, the whole set of LLE and SLE data was correlated with the NRTL-PR equation. Deviations $\Delta \mathrm{x}_{2} / \mathrm{x}_{2} \%$ [LLE+SLE] thus obtained are given in Table 5 and LLE and SLE predictions are illustrated in Figs. 5a, 5b, 6a and 6b, respectively, for toluene, p-xylene, naphthalene and fluorene in water. For systems exhibiting LLE, it appears that the global modeling does not affect the prediction of the organic phase, while mole fractions in the aqueous phase are slightly underestimated. In the case of water-PAH systems, the global modeling allows predicting more accurate solubilities for binary mixtures with the highest experimental values $\left(>10^{-7}\right)$.

\section{Conclusion}

In this paper, we explored the capability of the NRTL-PR model to predict solid-liquid equilibria in water-PAH mixtures. For this purpose, we first considered high pressure phase equilibria of aromatic hydrocarbons in carbon dioxide or ethane, since solid solubilities of PAH are higher than in water. We showed that it is possible to accurately predict simultaneously VLE and SFE in those supercritical fluids, provided that all kinds of data are accounted for during the group contribution parameters fitting procedure.

We then applied our methodology to PAH-water systems. If parameters are fitted only on SLE data, satisfactory results were obtained for all the compounds, especially in the lowest solubility range. The consideration of both LLE and SLE data leads to an unmodified representation of the organic phase and a slight underestimation of aqueous phase solubilities, compared to our previous results concerning aromatic hydrocarbons-water mixtures; more accurate solubility predictions are obtained for solid PAH with the highest experimental values.

\section{Acknowledgements}

I. Raspo gratefully acknowledges financial support from the French spatial agency C.N.E.S. (Centre National des Etudes Spatiales).

\section{List of symbols}

$a=$ attractive term

$b=$ covolume

$g=$ molar Gibbs free energy

$G=$ Gibbs free energy

$H=$ enthalpy

$n=$ mole number

$P=$ pressure

$q=$ surface area factor

$Q_{k}=$ UNIFAC subgroup parameters

$r=$ volume area factor 
$R=$ ideal gas constant

$T=$ temperature

$v=$ molar volume

$x=$ mole fraction

$Z=$ compressibility factor

\section{Greek letters}

$\alpha=$ alpha function

$\alpha_{0}=$ non randomness factor

$\eta=$ packing fraction

$\varphi=$ fugacity coefficient

$\Gamma_{j i}=$ interaction parameter between molecules $j$ and $i$

$\Gamma_{L K}{ }^{(0)}, \Gamma_{L K}{ }^{(1)}=$ interaction parameters between main groups $K$ and $L$

$\omega=$ acentric factor

$\theta_{i K}=$ probability that a contact from molecule $i$ involves a main group $K$

$v_{i K}=$ number of main group $K$ in a molecule $i$

\section{Subscript}

$c=$ critical property

$f u s=$ fusion property

$i=$ pure component property

res $=$ residual property

\section{Superscript}

$E=$ excess property at constant pressure

$F=$ fluid phase

$L=$ liquid state

$r e f=$ reference property

$S=$ solid state

$s c l=$ subcooled liquid

\section{References}

[1] P.G. Wells, Mar. Pollut. Bull. 42 (2001) 251-252.

[2] S.K.Durlak, P.Biswas, J.Shi, M.J. Bernhard, Environ. Sci. Technol. 32 (1998) 2301-2307.

[3] J.J. Schauer, M.J.Kleeman, G.R.Cass, B.R.T.Simoneit, Environ. Sci. Technol. 35 (2001) 17161728.

[4] M.G. Zemanek, J.T.S. Pollard, S.L. Kenefick, S.E.Hrudey, Environ. Pollut. 98 (1997) 239-252.

[5] S.B. Hawthorne, Y. Yang, D.J. Miller, Anal. Chem. 66 (1994) 2912-1920.

[6] Y. Yang, S.B. Hawthorne, D.J. Miller, Environ. Sci. Technol. 31 (1997) 430-437.

[7] A.G. Carr, R. Mammucari, N.R. Foster, Chem. Eng. J. 172 (2011) 1-17.

[8] T. Fornari, R.P. Stateva, F.J. Señorans, G. Reglero, E. Ibañez, J. Super. Fluids. 46 (2008) 245251. 
[9] M.B. Oliveira, V.L. Oliveira, J.A.P. Coutinho, A.J. Queimada, Ind. Eng. Chem. Res. 48 (2009) 5530-5536.

[10] E. Neau, J. Escandell, C. Nicolas, Ind. Eng. Chem. Res. 49 (2010) 7589-7596.

[11] J. Escandell, E. Neau, C. Nicolas, Fluid Phase Equilib. 301 (2011) 80-97.

[12] E. Neau, J. Escandell, C. Nicolas, Ind. Eng. Chem. Res. 49 (2010) 7580-7588.

[13] S.H. Neau, G.L. Flynn, Pharm. Res. 7 (1990) 1157-1162.

[14] D.S. Mishra, S.H. Yalkowsky, Pharm. Res. 9 (1992) 958-959.

[15] G.D. Pappa, E.C. Voutsas, K. Magoulas, D.P. Tassios, Ind. Eng. Chem. Res., 44 (2005) 37993806.

[16] D.Y. Peng, D.B. Robinson, Ind. Chem. Fundam. 15 (1976) 59-64.

[17] E. Neau, J. Escandell, I. Raspo, Chem. Eng. Sci. 66 (2011), 4148-4156.

[18] A. Fredenslund, J. Gmehling, P. Rasmusen, Vapor-Liquid equilibrium using UNIFAC, Elsevier, Amsterdam, 1977.

[19] T. Holderbaum, J. Gmehling, Fluid Phase Equilib. 70 (1991) 251-265.

[20] E. Neau, I. Raspo, J. Escandell, C. Nicolas, O. Hernández-Garduza, Fluid Phase Equilib. 276 (2009), 156-164.

[21] G. Soave, Chem. Eng. Sci. 27 (1972) 1197-1340.

[22] D.B. Robinson, D.Y. Peng, RR-28 The Characterization of the Heptanes and Heavier Fractions for the GPA Peng-Robinson Programs, Gas Processors Association Research Report, EdmontonAlberta, 1978.

[23] S. Angus, B. Armstrong, K.M. de Reuck, International Thermodynamics Tables of the Fluid State Carbon Dioxide, Pergamon Press, Oxford, 1976.

[24] B.E. Poling, J.M. Prausnitz, J.P. O'Connell, The properties of Gases and Liquids, $5^{\text {th }}$ ed., McGraw-Hill, New York, 2004.

[25] R.D. Goodwin, Provisional Values for the Thermodynamic Functions of Ethane, American Gas Association, Research Report NBSIR 74-398, 1974.

[26] M. Skerget, Z. Novak-Pintaric, Z. Knez, Z. Kravanja, Fluid Phase Equilib. 203 (2002) 111-132.

[27] L. Constantinou, R. Gani, J.P. O’Connell, Fluid Phase Equilib. 103 (1995) 11-22.

[28] A.M. Chaudhury, Current Sci. 24 (1955) 80-81.

[29] R.C. Reid, J.M. Prausnitz, B.E. Poling, The properties of Gases and Liquids, $4^{\text {th }}$ ed., McGrawHill, New York, 1987.

[30] R.R. Dreisbach, Physical Properties of Chemical Compounds, Advances in Chemistry Series, ACS Publications, 1961.

[31] C. Nicolas, E. Neau, S. Meradji, I. Raspo, Fluid Phase Equilib. 232 (2005) 219-229.

[32] P. Karasek, J. Planeta, M. Roth, J. Chem. Eng. Data 51 (2006) 616-622. 
[33] M. Prasad, L.A. de Sousa, Current Sci. 6 (1937) 220-221.

[34] L. D. Gluzman, A. G. Nikitenko, Zh. Prikl. Khim. (St-Peterburg) 34 (1961) 626-628.

[35] S.T. Chung, K.S. Shing, Fluid Phase Equilib. 81 (1992) 321-341.

[36] M. McHugh, M.E. Paulaitis, J. Chem. Eng. Data 25 (1980) 326-329.

[37] M.E. Paulaitis, M. McHugh, C.P. Chai, Chem. Eng. Super. Fluid Cond. (1983) 139-158.

[38] Z. Suoqi, W. Renan, Y. Guanghua, J. Super. Fluids 8 (1995) 15-19.

[39] K.P. Johnston, D.H. Ziger, C.A. Eckert, Ind. Eng. Chem. Fundam. 21 (1982) 191-197.

[40] A.P. Abbott, S. Corr, N.E. Durling, E.G. Hope, J. Chem. Eng. Data 47 (2002) 900-905.

[41] H.-J. Chang, D.G. Morrell, J. Chem. Eng. Data 30 (1985) 74-78.

[42] J.-W. Chen, F.-N. Tsai, Fluid Phase Equilib. 107 (1995) 189-200.

[43] J.M. Dobbs, J.M. Wong, K.P. Johnston, J. Chem. Eng. Data 31 (1986) 303-308.

[44] J. Garcia-Gonzalez, M.J. Molina, F. Rodriguez, F. Mirada, J. Chem. Eng. Data 46 (2001) 918921.

[45] I. Goodarznia, F. Esmaeilzadeh, J. Chem. Eng. Data 47 (2002) 333-338.

[46] A. Kalaga, M. Trebble, J. Chem. Eng. Data 44 (1999) 1063-1066.

[47] R.T. Kurnik, S.J. Holla, R.C. Reid, J. Chem. Eng. Data 26 (1981) 47-51.

[48] L.-S. Lee, J.-H. Fu, H.-L. Hsu, J. Chem. Eng. Data 45 (2000) 358-361.

[49] G.-T. Liu, K. Nagahama, J. Super. Fluids 9 (1996) 152-160.

[50] S. Mitra, J.W. Chen, D.S. Viswanath, J. Chem. Eng. Data 33 (1988) 35-37.

[51] E. Reverchon, P. Russo, A. Stassi, J. Chem. Eng. Data 38 (1993) 458-460.

[52] S. Sako, K. Ohgaki, T. Katayama, J. Super. Fluids 1 (1988) 1-6.

[53] M. Sauceau, J. Fages, J.-J. Letourneau, D. Richon, Ind. Eng. Chem. Res. 39 (2000) 4609-4614.

[54] A. Stassi, R. Bettini, A. Gazzaniga, F. Giordano, A. Schiraldi, J. Chem. Eng. Data 45 (2000) 161-165.

[55] Y.V. Tsekhanskaya, M.B. Iomtev, E.V. Mushkina, Russ. J. Phys. Chem. 38 (1964) 1173-1176.

[56] Y.V. Tsekhanskaya, N.G. Roginskaya, E.V. Musshkina, Russ. J. Phys. Chem. 40 (1966) 11521156.

[57] A. Zuniga-Moreno, L.A. Galicia-Luna, L.E. Camacho-Camacho, Fluid Phase Equilib. 234 (2005) 151-163.

[58] F. Dongbao, S. Xuewen, Q. Yanhua, J. Xiaohui, Z. Suoqi, Fluid Phase Equilib. 251 (2007) 114120.

[59] K. Khimeche, P. Alessi, I. Kikic, A. Dahmani, J. Supercrit. Fluids 41 (2007) 10-19.

[60] A. Diefenbacher, M. Turk, J. Supercrit. Fluids 22 (2002) 175-184. 
[61] V. Pauchon, Z. Cisse, M. Chavret, J. Jose, J. of Supercritical Fluids 32 (2004) 115-121.

[62] R. Qilong, S. Baogen, H. Mei, W. Pingdong, J. Chem. Eng. Data 45 (2000) 464-466.

[63] W. Jingdai, C. Jizhong, Y. Yongrong, Fluid Phase Equilib. 220 (2004) 147-151.

[64] M. Sahihi, H.S. Ghaziaskar, M. Hajebrahimi, J. Chem. Eng. Data 55 (2010) 2596-2599.

[65] Y. Yamini, R.M. Fat'hi, N. Alizadeh, M. Shamsipur, Fluid Phase Equilib. 152 (1998) 299-305.

[66] H. Buxing, P. Ding-Yu, F. Cheng-Tze, G. Vilcsak, Can. J. Chem. Eng. 70 (1992) 1164-1171.

[67] D.M. Lamb, T.M. Barbara, J. Jonas, J. Phys. Chem. 90 (1986) 4210-4215.

[68] G. Madras, C. Erkey, A. Akgermann, J. Chem. Eng. Data 38 (1993) 422-423.

[69] I. Moradinia, A.S. Teja, Fluid Phase Equilib. 28 (1986) 199-209.

[70] Y. Iwai, Y. Mori, N. Hosotani, H. Higashi, T. Furuya, Y. Arai, K. Yamamoto, Y. Mito, J. Chem. Eng. data. 38 (1993) 509-511.

[71] G. Anitescu, L.L. Tavlarides, J. Super. Fluids 10 (1997) 175-189.

[72] J.M. Dobbs, K.P. Johnston, Ind. Eng. Chem. Res. 26 (1987) 1476-1482.

[73] F. Esmaeilzadeh, I. Goodarznia, J. Chem. Eng. Data 50 (2005) 49-51.

[74] J.W. Hampson, J. Chem. Eng Data 41 (1996) 97-100.

[75] E. Kosal, G.D. Holder, J. Chem. Eng. Data 32 (1987) 148-150.

[76] J. Kwiatkowski, Z. Lisicki, W. Majewski, Ber. Bunsenges. Phys. Chem. 88 (1984) 865-869.

[77] L. Qunsheng, Z. Zeting, Z. Chongli, L. Yancheng, Z. Qingrong, Fluid Phase Equilib. 207 (2003) 183-192.

[78] T.W. Zerda, B. Wiegand, J. Jonas, J. Chem. Eng. Data 31 (1986) 274-277.

[79] L. Barna, J.-M. Blanchard, E. Rauzy, C. Berro, J. Chem. Eng. Data 41 (1996) 1466-1469.

[80] K.D. Bartle, A.A. Clifford, S.A. Jafar, J. Chem. Eng. Data 35 (1990) 355-360.

[81] L.-S. Lee, J.-F. Huang, O.-X. Zhu, J. Chem. Eng. Data 46 (2001) 1156-1159.

[82] Y. Yamini, N. Bahramifar, J. Chem. Eng. Data 45 (2000) 53-56.

[83] T. Pang, E. McLaughlin, Ind. Eng. Chem. Proc. Des. Dev. 24 (1985) 1027-1032.

[84] K.D. Bartle, J. Chem. Eng. Data 35 (1990) 355-360.

[85] D.J. Miller, S.B. Hawthorne, A.A. Clifford, S. Zhu, J. Chem. Eng. Data 41 (1996) 779-786.

[86] W.J. Schmitt, R.C. Reid, J. Chem. Eng. Data 31 (1986) 204-212.

[87] G.I. Kaminishi, C. Yokoyama, S. Takahashi, Fluid Phase Equilib. 34 (1987) 83-99.

[88] M.K. Gupta, Y.-H. Li, B.J. Hulsey, R.L. Robinson Jr., J. Chem. Eng. Data 27 (1982) 55-57.

[89] P.G. Bendale, R.M. Enick, Fluid Phase Equilib., 94 (1994) 227-253.

[90] H. Inomata, K. Arai, S. Saito, Fluid Phase Equilib. 29 (1986) 225-232. 
[91] S. Laugier, A. Valtz, A. Chareton, D. Richon, H. Renon, RR-82 Vapor-Liquid Equilibria Measurements on the Systems Ethane-Tolune, Ethane-N-Propylbenzene, Ethane-Metaxylene, Ethane-Mesitylene, Ethane-Methylcyclohexane, Gas Processors Association Research Report, Edmonton-Alberta, 1984.

[92] D.S. Jan, F.N. Tsai, Ind. Eng. Chem. Res. 30 (1991) 1965-1970.

[93] M.W. Barrick, A.J. McRay, R.L. Robinson Jr., J. Chem. Eng. Data 32 (1987) 372-374.

[94] R.A. Harris, M. Wilken, K. Fischer, T.M. Letcher, J.D. Raal, D. Ramjugernath, Fluid Phase Equilib. 260 (2007) 60-64.

[95] M. Akiyoshi, T. Deguchi, I. Sanemasa, Bull. Chem. Soc. Jpn. 60 (1987) 3935-3939.

[96] L.J. Andrews, R.M. Keefer, J. Am. Chem. Soc. 71 (1949) 3644-3647.

[97] S. Banerjee, S.H. Yalkowsky, S.C. Valvani, Environ. Sci. Technol. 14 (1980) 1227-1229.

[98] R.L. Bohon, W.F. Claussen, J. Am. Chem. Soc. 73 (1951) 1571-1578.

[99] G.T. Coyle, T.C. Harmon, I.H. Suffet, Environ. Sci. Technol. 31 (1997) 384-389.

[100] R.P. Eganhouse, J.A. Calder, Geochim. Cosmochim. Acta 40 (1976) 555-561.

[101] M. Janado, Y. Yano, Y. Doi, H. Sakamoto, J. Solution Chem. 12 (1983) 741-754.

[102] D. Mackay, W.Y. Shiu, J. Chem. Eng. Data. 22 (1977) 399-402.

[103] M.M. Miller, S. Ghobdane, S.P. Wasik, Y.B. Tewari, D.E. Martire, J. Chem. Eng. Data 29 (1984) 184-190.

[104] A. Vesala, Acta Chem. Scand. Ser. A 28 (1974) 839-845.

[105] R.D. Wauchope, F.W. Getzen, J. Chem. Eng. Data 17 (1972) 38-41

[106] S. Sawamura, M. Tsuchiya, T. Ishigami, Y. Taniguchi, K. Suzuki, J. Solution Chem. 22 (1993) 727-732.

[107] D. Bennett, W.J. Canady, J. Am. Chem. Soc. 106 (1984) 910-915.

[108] R.M. Dickhut, A.W. Andren, D.E. Armstrong, J. Chem. Eng. Data 34 (1989) 438-443.

[109] J.E. Gordon, R.L. Thorne, J. Phys. Chem. 71 (1967) 4390-4399.

[110] S. Hilpert, Angew. Chem. 29 (1916) 57-59.

[111] H.B. Klevens, J. Phys. Chem. 54 (1950) 283-298.

[112] W.E. May, S.P. Wasik, D.H. Freeman, Anal. Chem. 50 (1978) 997-1000.

[113] W.E. May, S.P. Wasik, M.M. Miler, Y.B. Tewari, J.M. Brown-Thomas, J. Chem. Eng. Data 28 (1983) 197-200.

[114] D.J. Miller, S.B. Hawthorne, Anal. Chem. 70 (1998) 1618-1621.

[115] S. Mitchell, J. Chem. Soc. (1926) 1333-1336.

[116] F.P. Schwarz, S.P. Wasik, Anal. Chem. 48 (1976) 524-528.

[117] F.P. Schwarz, S.P. Wasik, J. Chem. Eng. Data 22 (1977) 270-273. 
[118] F.P. Schwarz, J. Chem. Eng. Data 22 (1977) 273-277.

[119] F.M. Van Meter, H.M. Neumann, J. Am. Chem. Soc. 98 (1976) 1382-1388.

[120] A. Vesala, H. Lonnberg, Acta Chem. Scand. Ser. A 34 (1980) 187-192.

[121] D.J. Miller, S.B. Hawthorne, A.M. Gizir, A.A. Clifford, J. Chem. Eng. Data 43 (1998) 10431047.

[122] S. Sawamura, J. Solution Chem. 29 (2000) 369-375.

[123] T.A. Andersson, K.M. Hartonen, M-L. Riekkola, J. Chem. Eng. Data 50 (2005) 1177-1783.

[124] P. Dohanyosova, V. Dohnal, D. Fenclova, Fluid Phase Equilib. 214 (2003) 151-167.

[125] R.I.S. Haines, S.I. Sandler, J. Chem. Eng. Data 40 (1995) 833-836.

[126] Y. Hashimoto, K. Tokura, K. Ozaki, W.M.J. Strachan, Chemosphere 11 (1982) 991-1001.

[127] H. Kishi, Y. Hashimoto, Chemosphere 18 (1989) 1749-1759.

[128] R.W. Walters, R.G. Luthy, Environ. Sci. Technol. 18 (1984) 395-403.

[129] W.W. Davis, M.E. Krahl, G.H.A. Cloves, J. Am. Chem. Soc. 64 (1942) 108-110.

[130] P. Karasek, J. Planeta, M. Roth, J. Chromatogr. A 1140 (2007) 195-204.

[131] W.E. May, S.P. Wasik, D.H. Freeman, Anal. Chem. 50 (1978) 175-179.

[132] P. Karasek, J. Planeta, Roth M., Ind. Eng. Chem. Res. 45 (2006) 4454-4460.

[133] A. Maczynski, D.G. Shaw, M. Goral, B. Wisniewska-Goclowska, A. Skrzecz, I. Owczarek, K. Blazej, M.C. Haulait-Pirson, G.T. Hefter, Z. Maczynska, A. Szafranski, C. Tsonopoulos, C.L. Young, J. Phys. Chem. Ref. Data 34 (2005) 477-552.

[134] D.G. Shaw, A. Maczynski, M. Goral, B. Wisniewska-Goclowska, A. Skrzecz, I. Owczarek, K. Blazej, M.C. Haulait-Pirson, G.T. Hefter, Z. Maczynska, A. Szafranski, J. Phys. Chem. Ref. Data 34 (2005) 1489-553.

[135] A. Maczynski, D.G. Shaw, M. Goral, B. Wisniewska-Goclowska, A. Skrzecz, I. Owczarek, K. Blazej, M.C. Haulait-Pirson, G.T. Hefter, F. Kapukyu, Z. Maczynska, A. Szafranski, C.L. Young, J. Phys. Chem. Ref. Data 34 (2005) 1399-487. 


\section{List of tables}

\section{Table 1}

Group contribution of the NRTL-PR model and surface area parameters $Q_{k}$ considered.

\section{Table 2}

Properties of pure compounds. Critical temperature, $T_{c}$, and pressure, $P_{c}$, acentric factor, $\omega$, melting temperature, $T_{m}$, normal fusion enthalpy, $\Delta_{f u s} H$, and solid molar volume, $v^{S}$.

\section{Table 3}

Modeling of solid PAH in supercritical carbon dioxide by means of the NRTL-PR model. Number of SFE data points, $N p$, percent deviations, $\Delta x_{2} / x_{2} \%$, on the solubility of PAH using parameters fitted on VLE+SFE data; $x_{2} *$ is the range of experimental solubilities and Ref. is the reference of experimental SFE data.

\section{Table 4}

Modeling of solid PAH in supercritical ethane by means of the NRTL-PR model. Number of SFE data points, $N p$, percent deviations, $\Delta x_{2} / x_{2} \%$, on the solubility of PAH using parameters fitted on VLE+SFE data; $x_{2} *$ is the range of experimental solubilities and Ref. is the reference of experimental SFE data.

\section{Table 5}

Modeling of solid PAH in water by means of the NRTL-PR model. Number of SLE data points, $N p$, percent deviations, $\Delta x_{2} / x_{2} \%$, on the solubility of PAH using parameters fitted on SLE data $\left(\Delta x_{2} / x_{2} \%\right.$ $[S L E])$ or on LLE+SLE data $\left(\triangle x_{2} / x_{2} \%[L L E+S L E]\right) ; x_{2} *$ is the range of experimental solubilities and Ref. is the reference of experimental SLE data. 


\section{Table 1}

Group contribution of the NRTL-PR model and surface area parameters $Q_{k}$ considered.

\begin{tabular}{cccc}
\hline Main Groups $\boldsymbol{K}$ & Subgroups $\boldsymbol{k}$ & $\boldsymbol{Q}_{\boldsymbol{k}}$ & $\boldsymbol{R} \boldsymbol{e f}$. \\
\hline \multirow{4}{*}{ Alkanes } & $\mathrm{CH}_{3}$ & 0.848 & {$[18]$} \\
& $\mathrm{CH}_{2}$ & 0.540 & {$[18]$} \\
& $\mathrm{CH}$ & 0.228 & {$[18]$} \\
$\mathrm{C}$ & 0.000 & {$[18]$} \\
Naphthens & $\mathrm{CH}_{2}$ & 0.540 & {$[18]$} \\
& $\mathrm{CH}$ & 0.228 & {$[18]$} \\
Aromatics & $\mathrm{C}$ & 0.000 & {$[18]$} \\
Ethane & $\mathrm{CH}$ & 0.400 & {$[18]$} \\
Carbon dioxide & $\mathrm{C}$ & 0.120 & {$[18]$} \\
Water & $\mathrm{C}_{2} \mathrm{H}_{6}$ & 1.696 & {$[18]$} \\
& $\mathrm{CO}_{2}$ & 0.982 & {$[19]$} \\
& $\mathrm{H}_{2} \mathrm{O}$ & 1.400 & {$[18]$} \\
\hline
\end{tabular}


Table 2

Properties of pure compounds. Critical temperature, $T_{c}$, and pressure, $P_{c}$, acentric factor, $\omega$, melting temperature, $T_{m}$, normal fusion enthalpy, $\Delta_{f u s} H$, and solid molar volume, $v^{S}$.

\begin{tabular}{|c|c|c|c|c|c|c|c|c|c|c|}
\hline Compounds & $T_{c}(K)$ & $P_{c}(b a r)$ & Ref. & $\omega$ & $\operatorname{Ref}$. & $T_{m}(K)$ & $\Delta_{f u s} H(k J / m o l)$ & Ref. & $v^{S}\left(m^{3} / m o l\right)$ & $\operatorname{Ref}$. \\
\hline $\mathrm{CO}_{2}$ & 304.21 & 73.83 & {$[23]$} & 0.2250 & {$[24]$} & - & - & - & - & - \\
\hline $\mathrm{C}_{2} \mathrm{H}_{6}$ & 305.37 & 48.76 & {$[25]$} & 0.0990 & & - & - & - & - & - \\
\hline $\mathrm{H}_{2} \mathrm{O}$ & 647.14 & 220.6 & {$[24]$} & - & - & - & - & - & - & - \\
\hline biphenyl & 773.00 & 33.80 & [24] & 0.4040 & {$[24]$} & 344.15 & 18.800 & {$[26]$} & $1.310 \times 10^{-4}$ & [26] \\
\hline triphenyl methane & 841.16 & 21.83 & $*$ & 0.6729 & $* *$ & 365.60 & 20.920 & $* * *$ & $2.140 \times 10^{-4}$ & [28] \\
\hline naphthalene & 748.40 & 40.51 & [26] & 0.3020 & {$[26]$} & 353.50 & 19.060 & [26] & $1.100 \times 10^{-4}$ & [26] \\
\hline 2-methyl naphthalene & 761.00 & 35.00 & [29] & 0.3820 & {$[29]$} & 330.64 & 17.500 & [9] & $1.419 \times 10^{-4}$ & [30] \\
\hline 2,3-dimethyl naphthalene & 764.56 & 29.52 & $*$ & 0.4283 & $*$ & 377.95 & 25.101 & {$[31]$} & $1.547 \times 10^{-4}$ & [31] \\
\hline 2,6-dimethyl naphthalene & 764.56 & 29.52 & $*$ & 0.4283 & $*$ & 383.32 & 25.055 & $* * *$ & $1.392 \times 10^{-4}$ & [31] \\
\hline 2,7-dimethyl naphthalene & 764.56 & 29.52 & $*$ & 0.4283 & $*$ & 368.85 & 23.349 & {$[24]$} & $1.564 \times 10^{-4}$ & [30] \\
\hline anthracene & 826.54 & 30.85 & $*$ & 0.7376 & $* *$ & 489.75 & 28.830 & {$[26]$} & $1.426 \times 10^{-4}$ & [26] \\
\hline phenanthrene & 826.54 & 30.85 & $*$ & 0.6280 & $* *$ & 373.65 & 16.460 & {$[26]$} & $1.510 \times 10^{-4}$ & [26] \\
\hline acenaphtene & 809.46 & 33.82 & $*$ & 0.3896 & $* *$ & 366.56 & 21.460 & [32] & $1.262 \times 10^{-4}$ & [33] \\
\hline fluorene & 817.53 & 32.21 & $*$ & 0.3045 & $* *$ & 387.94 & 19.580 & [32] & $1.393 \times 10^{-4}$ & [31] \\
\hline fluoranthene & 873.82 & 29.40 & $*$ & 0.6527 & $* *$ & 383.36 & 18.728 & [32] & $1.793 \times 10^{-4}$ & [34] \\
\hline pyrene & 874.81 & 29.53 & $*$ & 0.7564 & $* *$ & 423.80 & 17.360 & $* * *$ & $1.585 \times 10^{-4}$ & [31] \\
\hline
\end{tabular}

* calculated from the group contributions of [27].

** fitted value.

*** http://webbook.nist.gov/chemistry/. 


\section{Table 3}

Modeling of solid PAH in supercritical carbon dioxide by means of the NRTL-PR model. Number of SFE data points, $N p$, percent deviations, $\Delta x_{2} / x_{2} \%$, on the solubility of PAH using parameters fitted on VLE+SFE data; $x_{2} *$ is the range of experimental solubilities and Ref. is the reference of experimental SFE data.

\begin{tabular}{|c|c|c|c|c|c|c|}
\hline Compounds & $N p$ & $T_{\text {range }}(K)$ & $P_{\text {range }}($ bar $)$ & $\Delta x_{2} / x_{2} \%$ & $x_{2} *$ & Ref. \\
\hline biphenyl & 82 & $308-333$ & $80-538$ & 22.45 & $3.1 \times 10^{-4}-1.1 \times 10^{-1}$ & {$[35-38]$} \\
\hline triphenyl methane & 22 & $303-323$ & $70-414$ & 31.29 & $9.4 \times 10^{-6}-2.5 \times 10^{-3}$ & [39] \\
\hline naphthalene & 470 & $308-333$ & $61-500$ & 18.78 & $2.4 \times 10^{-4}-6.4 \times 10^{-2}$ & {$[35,36,38,40-68]$} \\
\hline 2,3-dimethyl naphthalene & 20 & $308-328$ & $99-280$ & 19.57 & $1.3 \times 10^{-3}-9.0 \times 10^{-3}$ & {$[47,69]$} \\
\hline 2,6-dimethyl naphthalene & 23 & $308-328$ & $79-280$ & 20.08 & $3.0 \times 10^{-4}-9.2 \times 10^{-3}$ & {$[47,70]$} \\
\hline 2,7-dimethyl naphthalene & 10 & $308-328$ & $88-249$ & 13.20 & $7.4 \times 10^{-4}-1.2 \times 10^{-2}$ & {$[70]$} \\
\hline anthracene & 282 & $293-368$ & $69-1156$ & 38.94 & $3.3 \times 10^{-6}-4.4 \times 10^{-4}$ & {$[39,71-78]$} \\
\hline phenanthrene & 306 & $303-343$ & $78-414$ & 24.31 & $2.1 \times 10^{-5}-4.1 \times 10^{-3}$ & {$[38,39,43,47,71,73,76,79-81]$} \\
\hline acenaphtene & 45 & $308-348$ & $121-356$ & 53.55 & $1.3 \times 10^{-3}-1.4 \times 10^{-2}$ & {$[82]$} \\
\hline fluorene & 187 & $303-343$ & $70-483$ & 16.81 & $1.0 \times 10^{-5}-9.2 \times 10^{-3}$ & {$[39,76,80,83]$} \\
\hline fluoranthene & 73 & $308-348$ & $86-355$ & 56.76 & $9.1 \times 10^{-6}-1.5 \times 10^{-3}$ & {$[79,82]$} \\
\hline pyrene & 254 & $308-373$ & $80-483$ & 25.69 & $2.7 \times 10^{-6}-1.6 \times 10^{-3}$ & {$[39,71,84,85]$} \\
\hline
\end{tabular}




\section{Table 4}

Modeling of solid PAH in supercritical ethane by means of the NRTL-PR model. Number of SFE data points, $N p$, percent deviations, $\Delta x_{2} / x_{2} \%$, on the solubility of PAH using parameters fitted on VLE+SFE data; $x_{2} *$ is the range of experimental solubilities and Ref. is the reference of experimental SFE data.

\begin{tabular}{lcccccc}
\hline Compounds & $\boldsymbol{N p}$ & $\boldsymbol{T}_{\text {range }}(\boldsymbol{K})$ & $\boldsymbol{P}_{\text {range }}(\boldsymbol{b a r})$ & $\boldsymbol{\Delta} \boldsymbol{x}_{\mathbf{2}} / \boldsymbol{x}_{\mathbf{2}} \boldsymbol{\%}$ & $\boldsymbol{x}_{2} *$ & $\boldsymbol{R e f}$ \\
\hline biphenyl & 10 & $308-318$ & $70-300$ & 29.30 & $1.0 \times 10^{-2}-6.2 \times 10^{-2}$ & {$[86]$} \\
triphenyl methane & 20 & $303-323$ & $50-400$ & 39.69 & $2.4 \times 10^{-4}-5.6 \times 10^{-3}$ & {$[39]$} \\
naphthalene & 69 & $293-328$ & $40-360$ & 23.95 & $1.8 \times 10^{-4}-1.4 \times 10^{-1}$ & {$[39,86]$} \\
anthracene & 87 & $313-343$ & $100-500$ & 50.20 & $4.2 \times 10^{-5}-4.2 \times 10^{-4}$ & {$[39,71]$} \\
phenanthrene & 83 & $303-328$ & $50-450$ & 36.88 & $2.0 \times 10^{-4}-1.1 \times 10^{-2}$ & {$[39,71,86]$} \\
pyrene & 15 & 333 & $100-350$ & 40.15 & $2.5 \times 10^{-4}-1.2 \times 10^{-3}$ & {$[71]$} \\
\hline
\end{tabular}




\section{Table 5}

Modeling of solid PAH in water by means of the NRTL-PR model. Number of SLE data points, $N p$, percent deviations, $\Delta x_{2} / x_{2} \%$, on the solubility of PAH using parameters fitted on SLE data $\left(\triangle x_{2} / x_{2} \%\right.$ [SLE]) or on LLE+SLE data $\left(\triangle x_{2} / x_{2} \%\right.$ [LLE+SLE]); $x_{2} *$ is the range of experimental solubilities and Ref. is the reference of experimental SLE data.

\begin{tabular}{|c|c|c|c|c|c|c|}
\hline Compounds & $N p$ & $T_{\text {range }}(K)$ & $\Delta x_{2} / x_{2} \%[S L E]$ & $\Delta x_{2} / x_{2} \%[L L E+S L E]$ & $x_{2}^{*}$ & $\operatorname{Ref}$. \\
\hline Biphenyl & 40 & $273-337$ & 65.59 & 39.50 & $3.1 \times 10^{-7}-5.4 \times 10^{-6}$ & [95-105] \\
\hline Naphthalene & 97 & $273-348$ & 52.18 & 26.77 & $1.7 \times 10^{-6}-4.4 \times 10^{-5}$ & {$[32,95,96,98-102,104,105,107-120]$} \\
\hline 2-methyl naphthalene & 2 & 298 & 40.31 & 10.16 & $3.1 \times 10^{-6}-3.2 \times 10^{-6}$ & {$[100,102]$} \\
\hline 2,3-dimethyl naphthalene & 2 & 298 & 64.60 & 38.10 & $2.3 \times 10^{-7}-3.5 \times 10^{-7}$ & {$[100,102]$} \\
\hline 2,6-dimethyl naphthalene & 2 & 298 & 51.96 & 18.24 & $1.5 \times 10^{-7}-2.3 \times 10^{-7}$ & {$[100,102]$} \\
\hline Anthracene & 96 & $273-483$ & 41.98 & 201.69 & $1.0 \times 10^{-9}-2.2 \times 10^{-4}$ & {$[95,102,105,111-113,116,118,123-128]$} \\
\hline Phenanthrene & 54 & $273-363$ & 53.34 & 237.25 & $3.9 \times 10^{-8}-3.3 \times 10^{-6}$ & {$[96,100,102,104,105,111,118,122,128-131]$} \\
\hline Acenaphtene & 23 & $273-348$ & 39.19 & 12.79 & $1.7 \times 10^{-7}-5.0 \times 10^{-6}$ & {$[97,100,102,104,105,125,128]$} \\
\hline Fluorene & 34 & $273-383$ & 10.09 & 50.86 & $7.2 \times 10^{-8}-1.6 \times 10^{-5}$ & {$[102,105,112,113,128,132]$} \\
\hline
\end{tabular}





\section{List of figures}

Figure 1. SFE of gas-PAH systems using the NRTL-PR model.

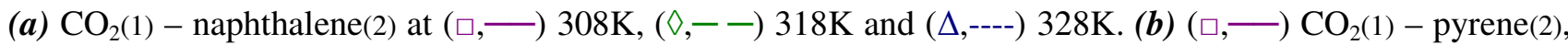
$(\diamond,--) \mathrm{CO}_{2}(1)-$ phenanthrene(2), $(\Delta,---) \mathrm{CO}_{2}(1)-$ fluorene(2) and $(\circ,-\cdots-) \mathrm{CO}_{2}(1)-$ biphenyl(2) at $308 \mathrm{~K}$. (c) $\mathrm{C}_{2} \mathrm{H}_{6}(1)-$ naphthalene(2) at $(\square,-) 298 \mathrm{~K}$ and $(\diamond,--) 308 \mathrm{~K}$. (d) (,,-$) \mathrm{C}_{2} \mathrm{H}_{6}(1)-$ anthracene $(2),(\diamond,--)$ $\mathrm{C}_{2} \mathrm{H}_{6}(1)-$ pyrene $(2)$ and $(\Delta,----) \mathrm{C}_{2} \mathrm{H}_{6}(1)-$ phenanthrene (2) at $333 \mathrm{~K}$. [Experimental data references given in Tables 3 and 4]

Figure 2. VLE of gas-aromatic hydrocarbon systems using the NRTL-PR model.

(a) $\mathrm{CO}_{2}(1)-$ benzene(2) at $(\square,-)$ ) 273K [87], $(\diamond,--) 313 \mathrm{~K}[88],(\Delta,---) 347 \mathrm{~K}[89]$ and $(\circ,-\cdots-) 414 \mathrm{~K}[90]$. (b) $\mathrm{C}_{2} \mathrm{H}_{6}(1)-$ toluene(2) [91] at $(\square,-) 313 \mathrm{~K},(\diamond,--) 393 \mathrm{~K}$ and $(\Delta,---) 473 \mathrm{~K}$. (c) $\mathrm{CO}_{2}(1)-$ naphthalene(2) at

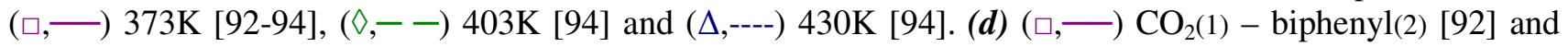
$(\diamond,--) \mathrm{CO}_{2}(1)-$ phenanthrene(2) [93] at $423 \mathrm{~K}$.

Figure 3. LLE of water-aromatic hydrocarbon systems using NRTL-PR [LLE] (-) parameters: mole fraction of aromatic hydrocarbon in the aqueous phase $x_{2}^{A q}(\diamond)$ and of water in the hydrocarbon phase $x_{l}{ }^{\text {Org }}(\square)$.

(a) Water(1) - benzene(2) [133]: calculations performed under atmospheric pressure. (b) Water(1) - mxylene(2) [134]: calculations performed under $\mathrm{P}=10 \mathrm{MPa}$.

Figure 4. SLE of water-aromatic hydrocarbon systems using NRTL-PR [SLE] (-) parameters: solubility of PAH in water $x_{2}(\diamond)$ under atmospheric pressure.

(a) Water(1) - acenaphtene(2). (b) Water(1) - phenanthrene(2). [Experimental data references given in Table 5]

Figure 5. LLE of water-aromatic hydrocarbon systems using NRTL-PR [LLE] (-) or [LLE+SLE] $(--)$ parameters: mole fraction of aromatic hydrocarbon in the aqueous phase $x_{2}{ }^{A q}(\diamond)$ and of water in the hydrocarbon phase $x_{l}{ }^{O r g}(\square)$ under atmospheric pressure.

(a) Water(1) - toluene(2) [135]. (b) Water(1) - p-xylene(2) [134].

Figure 6. SLE of water-aromatic hydrocarbon systems using NRTL-PR [SLE] (-) or [LLE+SLE] $(--)$ parameters: solubility of PAH in water $x_{2}(\diamond)$.

(a) Water(1) - naphthalene(2): calculations performed under atmospheric pressure. (b) Water(1) - fluorene(2): calculations performed under $\mathrm{P}=5 \mathrm{MPa}$. [Experimental data references given in Table 5] 

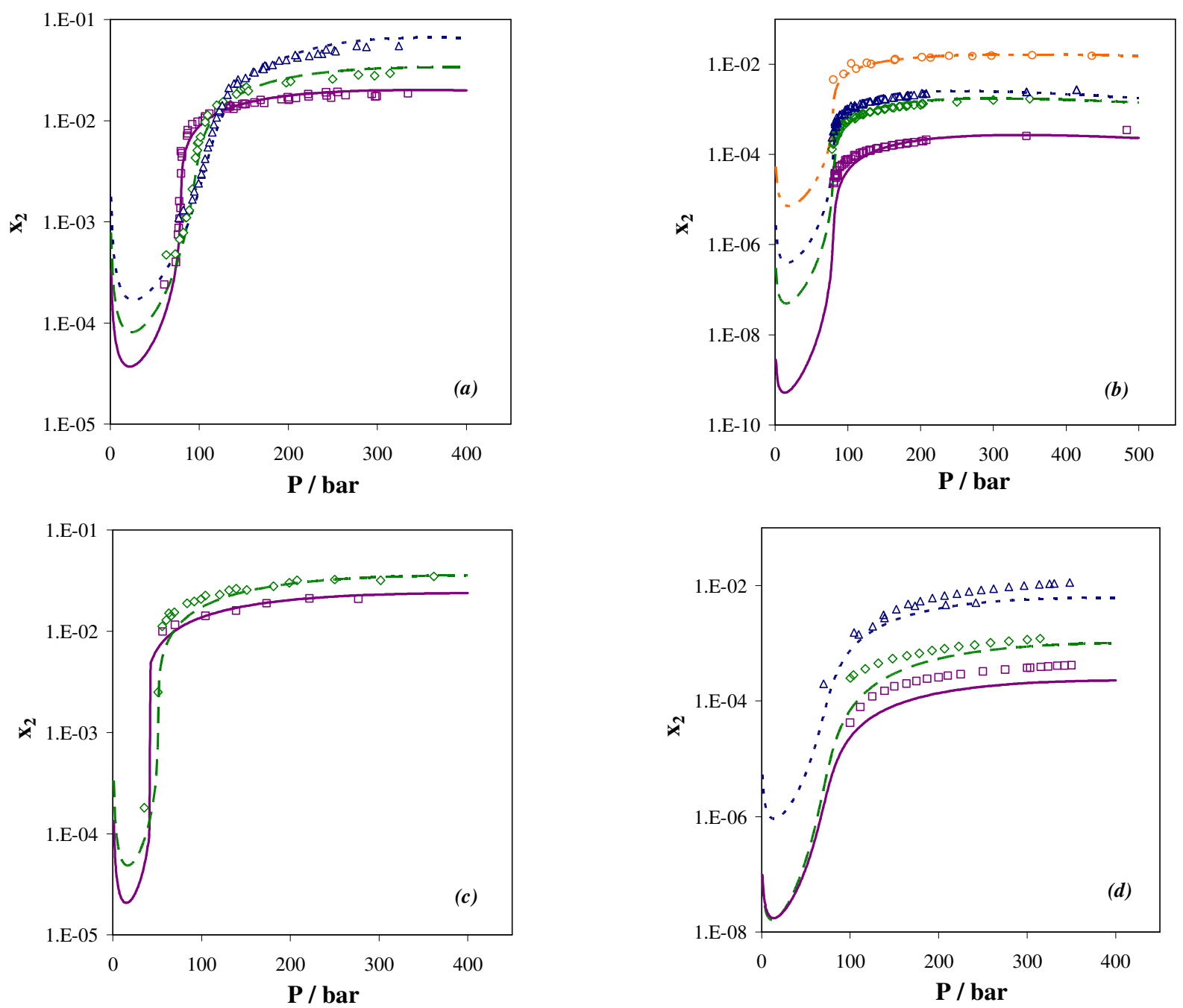

Figure 1. SFE of gas-PAH systems using the NRTL-PR model.

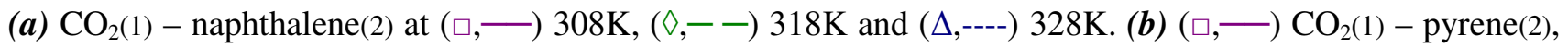
$(\diamond,--) \mathrm{CO}_{2}(1)$ - phenanthrene(2), ( $\left.\Delta,----\right) \mathrm{CO}_{2}(1)-$ fluorene(2) and $(\circ,-\cdots-) \mathrm{CO}_{2}(1)-$ biphenyl(2) at $308 \mathrm{~K}$. (c) $\mathrm{C}_{2} \mathrm{H}_{6}(1)-$ naphthalene(2) at $(\square,-) 298 \mathrm{~K}$ and $(\diamond,--) 308 \mathrm{~K}$. (d) (,$\left.-\longrightarrow\right) \mathrm{C}_{2} \mathrm{H}_{6}(1)-$ anthracene $(2),(\diamond,--)$ $\mathrm{C}_{2} \mathrm{H}_{6}(1)-$ pyrene(2) and $(\Delta,----) \mathrm{C}_{2} \mathrm{H}_{6}(1)-$ phenanthrene (2) at $333 \mathrm{~K}$. [Experimental data references given in Tables 3 and 4] 

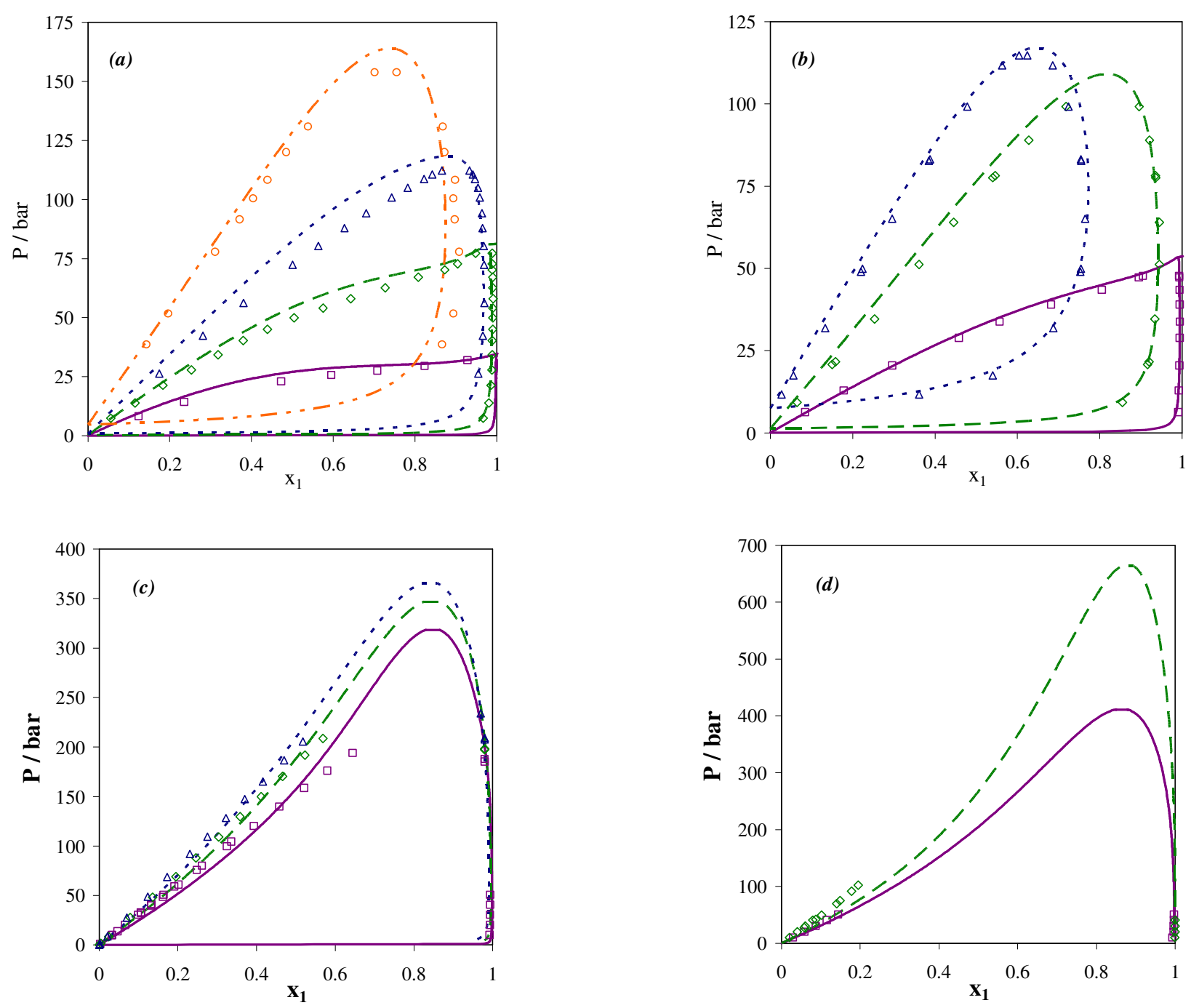

Figure 2. VLE of gas-aromatic hydrocarbon systems using the NRTL-PR model.

(a) $\mathrm{CO}_{2}(1)-$ benzene(2) at $(\square,-)$ ) 273K [87], $(\diamond,--) 313 \mathrm{~K}[88],(\Delta,---) 347 \mathrm{~K}[89]$ and $(\circ,-\cdots-) 414 \mathrm{~K}[90]$. (b) $\mathrm{C}_{2} \mathrm{H}_{6}(1)-$ toluene(2) [91] at $(\square,--) 313 \mathrm{~K},(\diamond,--) 393 \mathrm{~K}$ and $(\Delta,---) 473 \mathrm{~K}$. (c) $\mathrm{CO}_{2}(1)-$ naphthalene(2) at

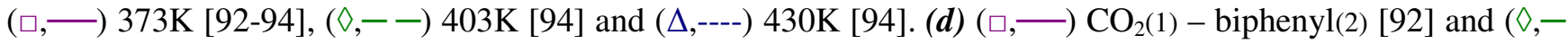
-) $\mathrm{CO}_{2}(1)$ - phenanthrene(2) [93] at $423 \mathrm{~K}$. 

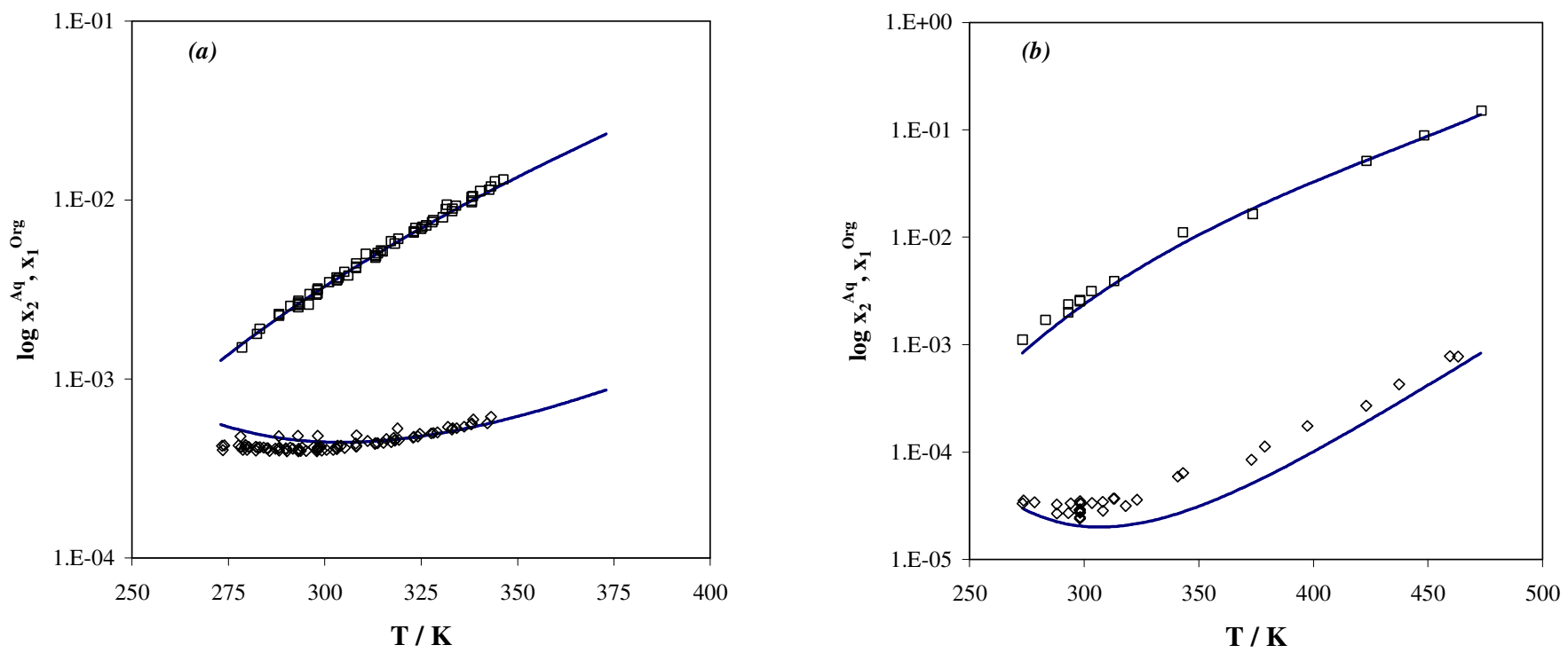

Figure 3. LLE of water-aromatic hydrocarbon systems using NRTL-PR [LLE] (-) parameters: mole fraction of aromatic hydrocarbon in the aqueous phase $x_{2}{ }^{A q}(\diamond)$ and of water in the hydrocarbon phase $x_{1}{ }^{\text {Org }}(\square)$.

(a) Water(1) - benzene(2) [133]: calculations performed under atmospheric pressure. (b) Water(1) - m-xylene(2) [134]: calculations performed under $\mathrm{P}=10 \mathrm{MPa}$. 

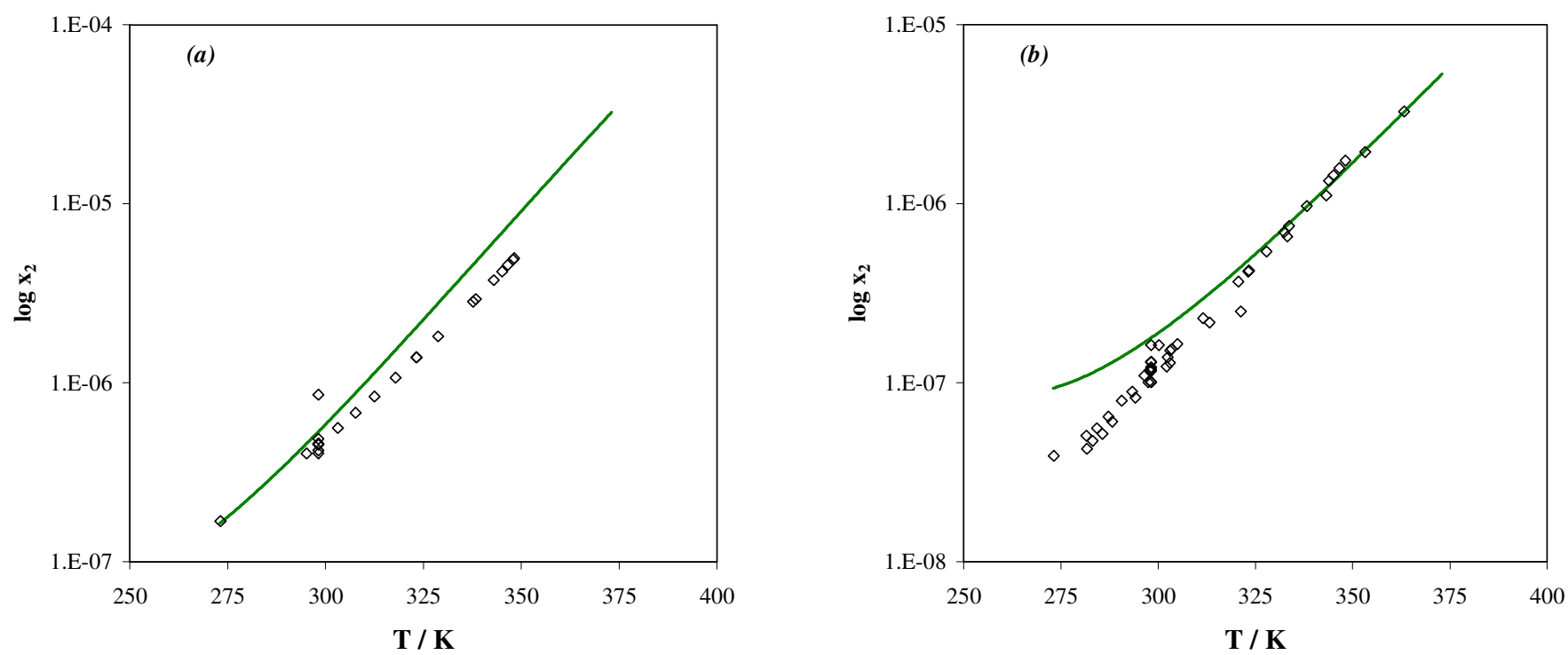

Figure 4. SLE of water-aromatic hydrocarbon systems using NRTL-PR [SLE] (-) parameters: solubility of PAH in water $x_{2}(\diamond)$ under atmospheric pressure.

(a) Water(1) - acenaphtene(2). (b) Water(1) - phenanthrene(2). [Experimental data references given in Table 5] 

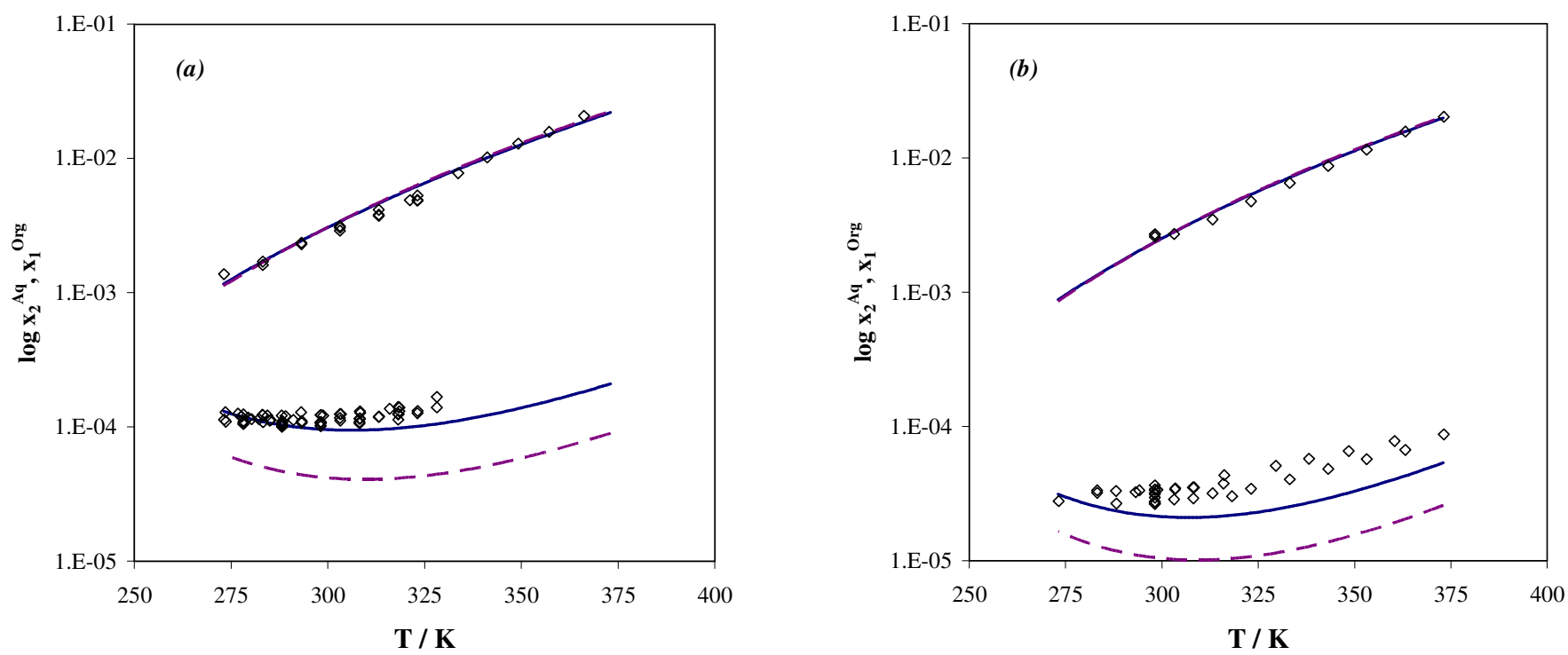

Figure 5. LLE of water-aromatic hydrocarbon systems using NRTL-PR [LLE] (-) or [LLE+SLE] (-) parameters: mole fraction of aromatic hydrocarbon in the aqueous phase $x_{2}{ }^{A q}(\diamond)$ and of water in the hydrocarbon phase $x_{1}{ }^{\mathrm{Org}}(\square)$ under atmospheric pressure.

(a) Water(1) - toluene(2) [135]. (b) Water(1) - p-xylene(2) [134]. 

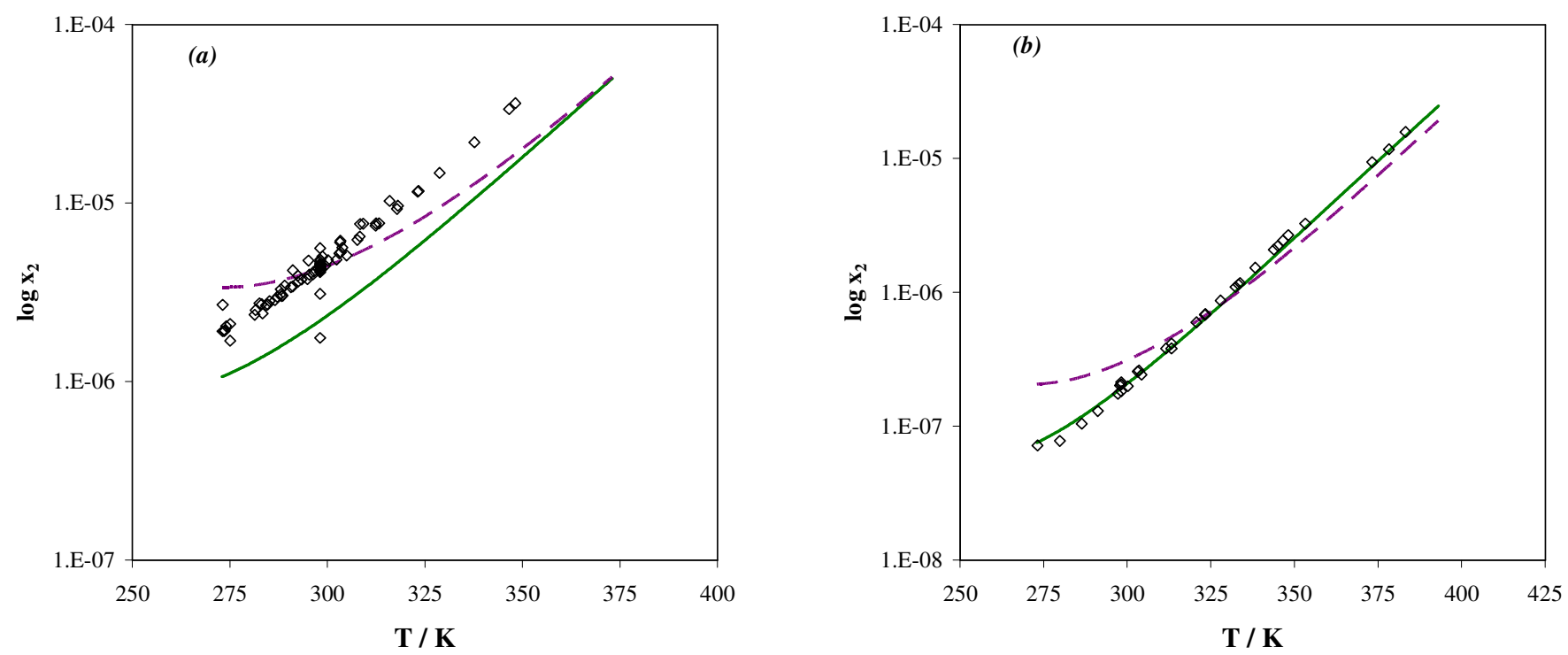

Figure 6. SLE of water-aromatic hydrocarbon systems using NRTL-PR [SLE] (-) or [LLE+SLE] (-) parameters: solubility of PAH in water $x_{2}(\diamond)$.

(a) Water(1) - naphthalene(2): calculations performed under atmospheric pressure. (b) Water(1) - fluorene(2): calculations performed under $\mathrm{P}=5 \mathrm{MPa}$. [Experimental data references given in Table 5] 